УДК: 615.072

DOI:10.18413/2313-8955-2017-3-4-51-60

Селютин О.А.

ОБЕСПЕЧЕНИЕ КАЧЕСТВА ЛЕКАРСТВЕННЫХ ПРЕПАРАТОВ
НА ОСНОВЕ ПРИНЦИПА КОМПЛЕКСНОГО
МОНИТОРИНГА-ЭКСПЕРТИЗЫ ОБРАЗЦОВ
И ИНФОРМАЦИОННОГО СКРИНИНГА

Бюджетное Учреждение Здравоохранения Воронежской Области «Воронежский Центр

Контроля Качества и Сертификации Лекарственных Средств»

(БУ ВО «Воронежский ЦКК и СЛС»), ул. Писателя Маршака, 1, г. Воронеж, 394051, Россия

E-mail:1156300@bsu.edu.ru

\begin{abstract}
Аннотация. Проблема контроля качества лекарственных средств на всех этапах обращения в условиях современной экономической ситуации Российской Федерации, в том числе и Воронежской области, на сегодняшний день остается не решенной. Установлено, что одной из причин присутствия лекарственных препаратов ненадлежащего качества на фармацевтическом рынке является недостаточный обмен информацией между субъектами обращения фармацевтической продукции и недостаток контроля ее качества. Поэтому в рамках данной статьи был проведен обзор механизмов и эффективности работы систем мониторинга качества ввозимых серий лекарственных препаратов на территории Воронежской области.
\end{abstract}

Ключевые слова: контроль качества; скрининг; эффективность.

\title{
O.A. Selyutin
}

\section{PROVISION OF THE MEDICINES QUALITY ON THE BASIS OF COMPLEX MONITORING AND SAMPLES EXAMINATION AND INFORMATION SCREENING}

Budgetary Health Care Institution of the Voronezh Region "Voronezh Center for Quality Assurance and Certification of Medicinal Products", Writer Marshak str., 1, Voronezh, 394051, Russia. E-mail:1156300@bsu.edu.ru

\begin{abstract}
The problem of quality control for medicines within all steps of their circulation in Russian Federation and Voronezh region has not been solved yet. It's well-known that the most leading reasons for presence of low-quality medicines in the pharmaceutical market are lack of informational exchange between pharmaceutical subjects and irresponsible quality control of pharmaceutical products. That is why in this article the review of the working mechanisms and results of the quality control system for the imported medicines on the territory of Voronezh region.
\end{abstract}

Keywords: quality control; screening; efficiency of medicines; examination; fake medicines.

Введение. В настоящее время одним из ведущих способов удовлетворения потребности населения в лекарственных средствах (ЛС) является поддержка и мониторинг качества лекарственного обеспечения, которое предопределяет доступность как медицин- ской, так и фармацевтической помощи. В условиях современной экономической ситуации, складывающейся на отечественном фармацевтическом рынке, в целях обеспечения потребителей продукцией надлежащего уровня качества, организации, осуществляю- 
щие деятельность по обращению ЛС на различных этапах, находятся в поиске перспективных направлений и способов повышений конкурентоспособности. Достижение этой цели является возможным благодаря разработке и внедрению новой системы мониторинга качества и безопасности ЛС, в основу которой будет положена концепция управления качеством обращения ЛС, а также она будет соответствовать требованиям законодательных актов.

Безусловно, роль государственной системы качества ЛС приобретает особый статус, что связано со значительным ростом фармацевтического рынка, увеличением объемов нелегальной и фальсифицированной продукции, информатизацией общества, а также созданием условий межнациональной торговли. Федеральным законом № 61-Ф3 от 12.04.2010 «Об обращении лекарственных средств» установлено, что полномочиями по государственному надзору в сфере обращения ЛС наделены федеральные органы исполнительной власти. Фактически, своевременное обнаружение и предупреждение реализации фармацевтической продукции ненадлежащего качества осуществляется силами органов управления здравоохранением субъектов Российской Федерации, контрольноаналитических лабораторий региональных центров контроля качества ЛС и иными фармацевтическими организациями, осуществляющими деятельность на всех этапах обращения ЛС.

Необходимость радикального решения относительно присутствия недоброкачественных ЛС на региональных фармацевтических рынках, прежде всего, возникает как следствие недостаточного обеспечения информационного обмена между участниками обращения ЛС, низкой степени управления системой качества как медицинских, так и фармацевтических организаций, отсутствием отлаженных систем управления качеством в каждом сегменте фармацевтического рынка, недостаточно эффективного взаимодействия между службами контроля качества и координации их работы Федеральным Центром, низким уровнем информированности населе- ния по вопросам выявления и предупреждения реализации фальсифицированных и ненадлежащего качества ЛС. В совокупности изложенные факторы присутствия некачественных ЛС обуславливают актуальность совершенствования территориальных систем управления качеством ЛС на всех этапах обращения.

Результаты исследований в области совершенствования системы управления качеством на различных стадиях обращения ЛС посвящены таких ведущих ученых, как В.Л. Багирова, Л. В. Мошкова, Е.В. Неволина, С. Г. Сбоева, Р.У. Хабриева, Е.Е. Чупандина, Р.И. Ягудина, стали основой для разработки теоретических и методических подходов к внедрению систем управления качеством ЛС в отдельные сегменты фармацевтического рынка, а также к реформированию контрольно-разрешительной системы на федеральном уровне.

Однако в рамках существующей до настоящего времени проблемы оптимизации системы управления и контроля качества обращения ЛС на уровне регионов остается большое число вопросов, которым до сих пор не было уделено должного внимания.

На сегодняшний день распространение недоброкачественных и фальсифицированных лекарственных средств стало глобальной проблемой, так как ассортимент такой продукции расширяется. Фальсификация и распространение недоброкачественных лекарственных средств оказывает деструктивное влияние, во-первых, на здоровье и качество жизни человека, а также на экономику страны.

Вопросы своевременного выявления и оперативного изъятия из обращения Н и ФЛС находятся в центре внимания органов управления здравоохранения на федеральном и региональном уровнях.

Вопросам качества ЛС посвящены исследования следующих ученых: Арзамасцева А.П., Егорова В.А. Парфейниковой С.А., Тельновой Е.А., Хабриевой Р.У., Ягудиной Р.И. и других.

Однако даже подлинные и качественные ЛС под действием неблагоприятных внешних 
факторов могут стать опасными для жизни человека в результате потери их эффективности и возможности оказывать ожидаемое терапевтическое действие. Впервые история проблемы подделки лекарств берет свое начало в XIX веке, ведь именно тогда были описаны случаи, когда недобросовестные производители ЛС намеренно занижали содержание действующих веществ, либо полностью производили замену дорогостоящего компонента на вещество растительного или животного происхождения, не отличающийся внешне, но имеющего значительно низкую стоимость. Например, за рубежом были зафиксированы факты добавления в масла лимона и бергамота терпентинного масла (скипидара), рыбий жир заменялся отходами рыбного производства, полученных настаиванием в минеральных или кунжутных маслах, а мятные капли вопреки фармакопейной прописи изготавливали из настойки крапивы, смешивая ее с эфирным маслом перечной мяты.

Как и во всем мире, ЛС в России относятся к продуктам особо высокого спроса. Независимо от возраста, социального положения и финансовых возможностей, каждому человеку со временем приходится посещать аптеку и приобретать лекарственные препараты. Однако не редки случаи, когда после приема лекарства люди не выздоравливают, а дополнительно вызывают серьёзные осложнения своего физического здоровья. По данным Всемирной Организации Здравоохранения, смертность от лекарств занимает пятое место в мире, уступая только травмам, патологиям сердечно-сосудистой системы, онко- логическим и пульмонологическим заболеваниям.

Поэтому проблема качества актуально как никогда и сегодня остро стоит во всем мире. Когда говорят о некачественных лекарствах, часто употребляют самые различные слова: «контрафактные ЛС», «поддельные лекарства», «фальшивые лекарства». Согласно официальной статистике, каждый год выявляется от 3 до 12 \% некачественных лекарственных препаратов от общего оборота препаратов.

В России официально впервые поддельный лекарственный препарат был выявлен в 1997г. Начиная с этого времени, государством проводятся мероприятия по оптимизации сферы надзора и контроля за качеством лекарственной продукции. На 2017 г. по данным руководства Федеральной службы по надзору в сфере здравоохранения доля фальсифицированных лекарственных средств от общего числа выпущенных серий производителями составляет $0,01 \%$.

Статистические сведения доли выявленных некачественных лекарственных средств неоднозначны, и зависят от способа подсчета количественных и качественных данных упаковок и партий лекарственных средств, а так же отсутствия единой системы учета и контроля продвижения лекарственной продукции.

В том числе на эту цифру влияет социальная значимость указанной проблемы и мнение разнообразных средств массовой информации.

По данным службы Росздравнадзора за период с 2011 года до 9 месяца 2017 года сложилась следующая динамика выявления некачественной лекарственной продукции, представленная в таблице 1 .

Таблица 1

\section{Динамика выявления некачественных лекарственных препаратов} на российском фармацевтическом рынке

Table 1

Dynamics of revealing the low-quality medicines in Russian pharmaceutical market

\begin{tabular}{|c|c|c|c|c|c|c|c|}
\hline \multirow{2}{*}{ Тип продукции } & \multicolumn{7}{|c|}{ Период выявления } \\
\cline { 2 - 8 } & 2011 & 2012 & 2013 & 2014 & 2015 & 2016 & сентябрь 2017 \\
\hline $\begin{array}{c}\text { Недоброкачественные } \\
\text { ЛП }\end{array}$ & 422 & 329 & 225 & 299 & 317 & 281 & 172 \\
\hline $\begin{array}{c}\text { Фальсифицированные } \\
\text { ЛП }\end{array}$ & 16 & 13 & 12 & 3 & 9 & 10 & 6 \\
\hline
\end{tabular}


Как видно из данных таблицы 1, со временем количество выявленных ЛП ненадлежащего качества снижается, хотя, как и в целом по Российской Федерации, указанная выше проблема фальсифицированных и недоброкачественных лекарственных препаратов также присутствует и в Воронежской области.

На территории субъекта, даже по сравнению с регионами Центрального федерального округа, фармацевтический рынок значителен в своих объемах и представлен оптовыми компаниями - 50, медицинскими организациями -111 , розничными организациями - 392 (1363 объекта) и другими учреждениями, где в обращении находятся лекарственные препараты, в месяц оборот лекарственных средств составляет около 50 млн. упаковок, 8000 наименований, и 55000 партий лекарственных средств. (по данным БУ ВО «Воронежский центр контроля качества и сертификации лекарственных средств» (далее Центр).

Департаментом здравоохранения Воронежской области для предотвращения оборота фальсифицированных и недоброкачественных лекарственных средств, за последние годы создана многоуровневая система контроля качества лекарственных препаратов. Основой которой является экспертная организация - Центр.

Основные приоритеты данной системы заключаются в том, что созданные в регионе уровни мониторинга, включают в себя одновременно экспертизу качества лекарственных образцов, партий и их информационную обработку для подтверждения качества лекарственной продукции.

Этапами указанной выше системы являются:

I. Лабораторный контроль всех партий ЛП, поступающих в Воронежскую область от оптовых поставщиков.

II. Информационно-аналитический скрининг ЛП, находящихся в обращении в аптечной и лечебной сети, посредством единой информационной программы.

III. Мониторинг качества лекарственных средств (в медицинских и фармацевтических организациях).

IV. Мониторинг безопасности лекарственных средств.

V. Добровольная сертификация систем менеджмента качества медицинских и фармацевтических организаций «Фармконтроль».

Результаты исследования и их обсуждение.

На рис. 1 представлены результаты мониторинга качества ЛС с точки зрения фактов выявления недоброкачественной продукции за период с 2005 по 2007 года и с 2015 по 2017 года.
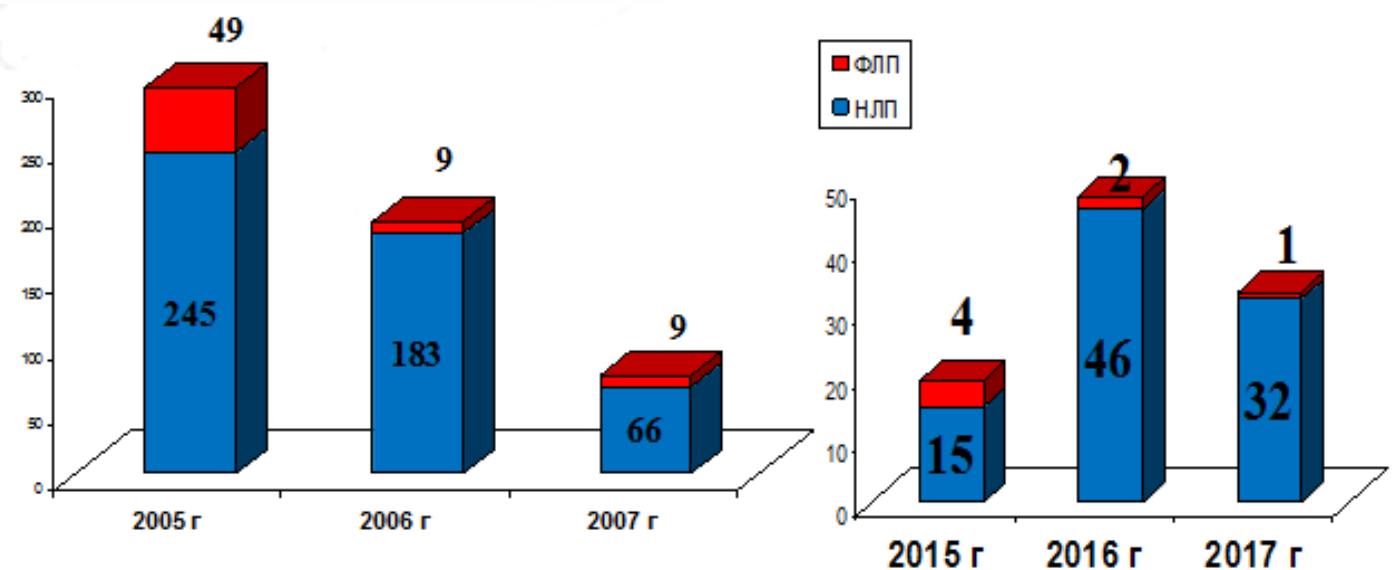

Рис. 1. Количество недоброкачественных и фальсифицированных ЛП согласно данным БУ ВО «Воронежского ЦКК и СЛС»

Fig. 1. Quantity of low-quality and fake medicines according to statistics, provided by quality control center in Voronezh 
Таким образом, можно сделать предварительный вывод о достаточной эффективности мониторинга качества лекарственной продукции на территории Воронежской области.
Результаты работы Центра за 5 лет представлены на рис. 2.

Контроль доброкачественности ЛС осуществляется на разных уровнях, схематично представленных на рис. 3.

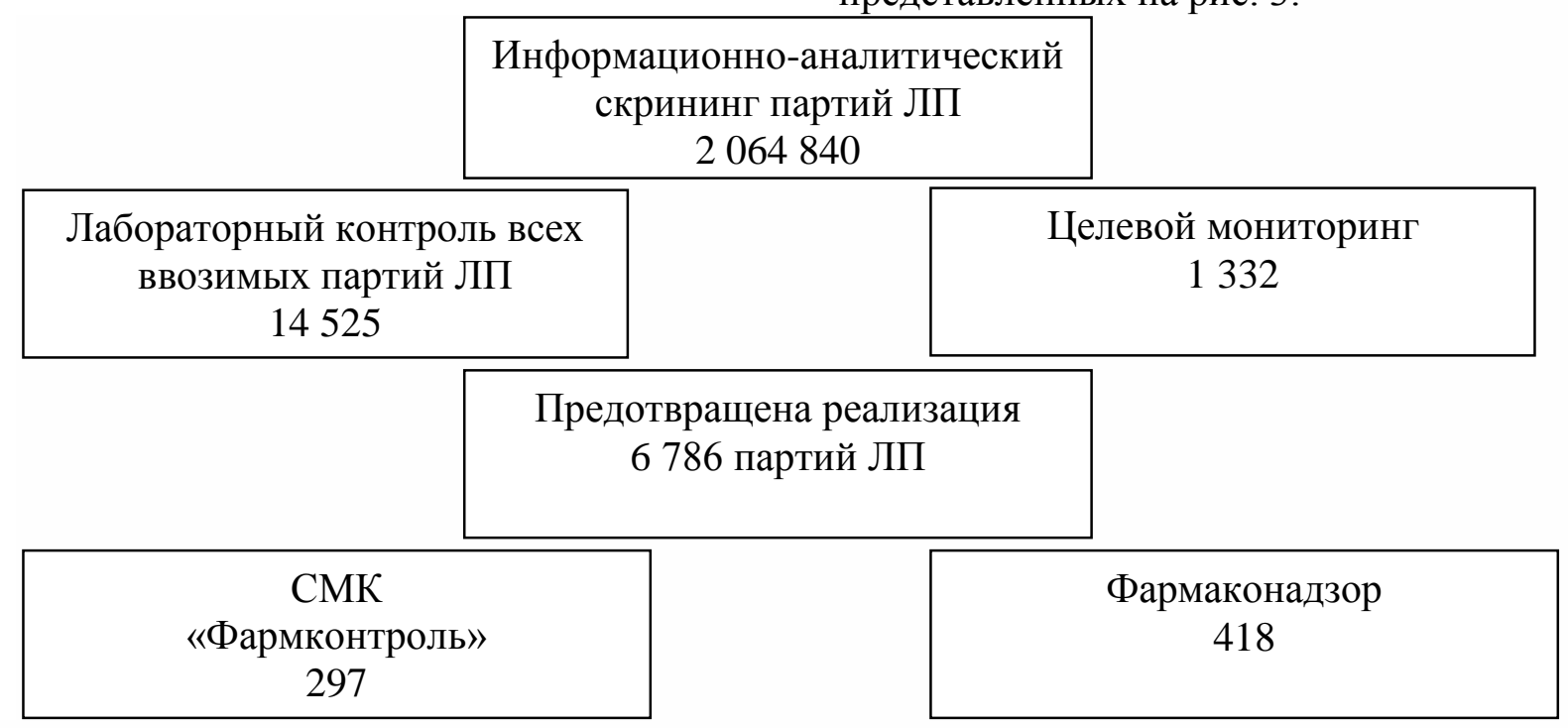

Рис. 2. Результаты работы Центра по этапам контроля за 2013-2017 гг.

Fig 2. Working results of quality control center within 2013-2017

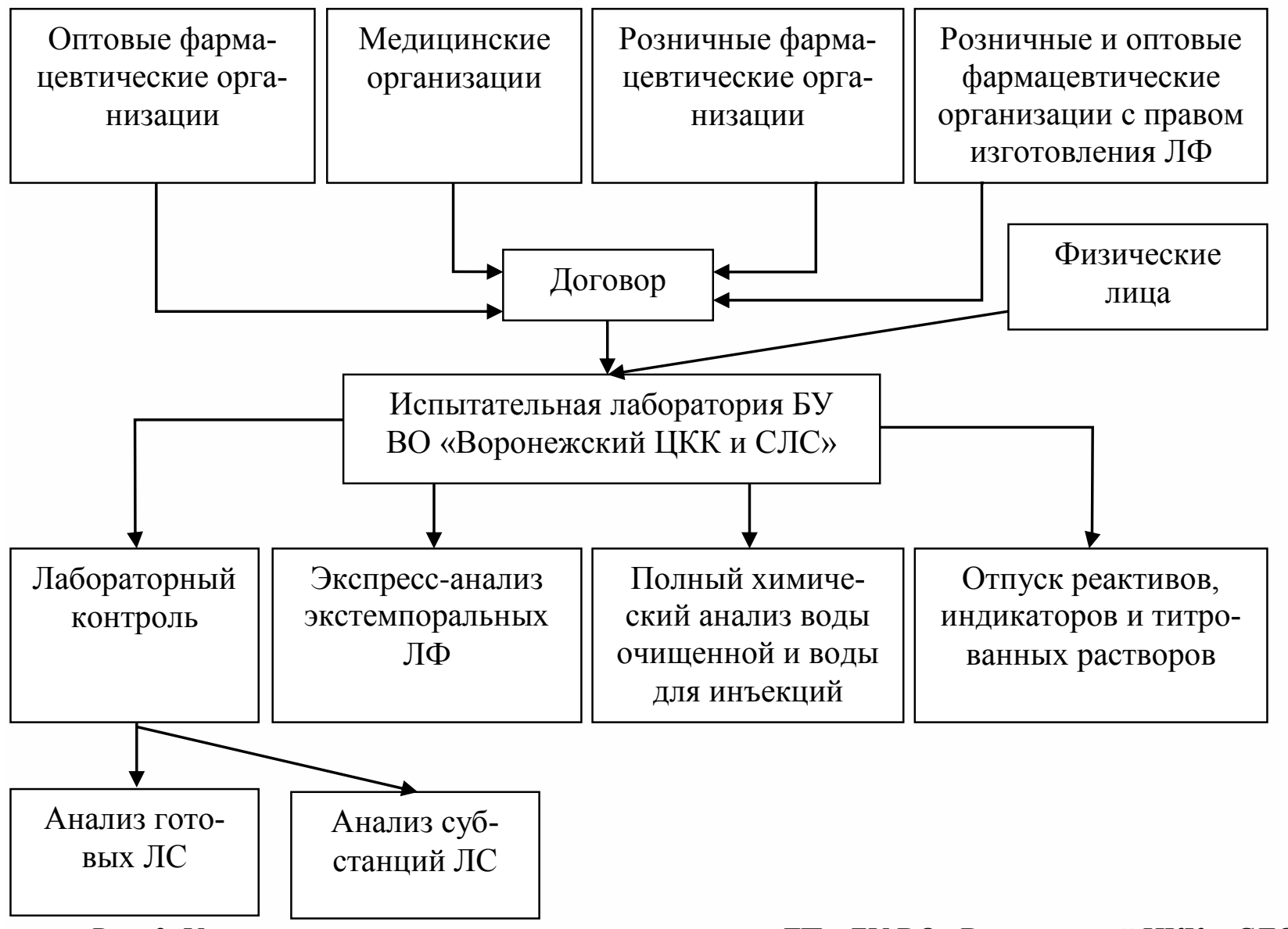

Рис. 3. Уровни осуществления мониторинга качества ЛП в БУ ВО «Воронежский ЦКК и СЛС» Fig. 3. Levels of quality control in quality control center in Voronezh 
Как видно из рис. 3, система мониторинга качества имеет стабильную и отлаженную структуру, благодаря чему ежегодно снижается число выявленных фальсифицированных и недоброкачественных лекарственных препаратов.
Информационно-аналитический также имеет свою устоявшуюся структуру, схематично представленную на рис. 4.

Система добровольной сертификации «Фармконтроль» также имеет свою структуру, представленную на рис. 5

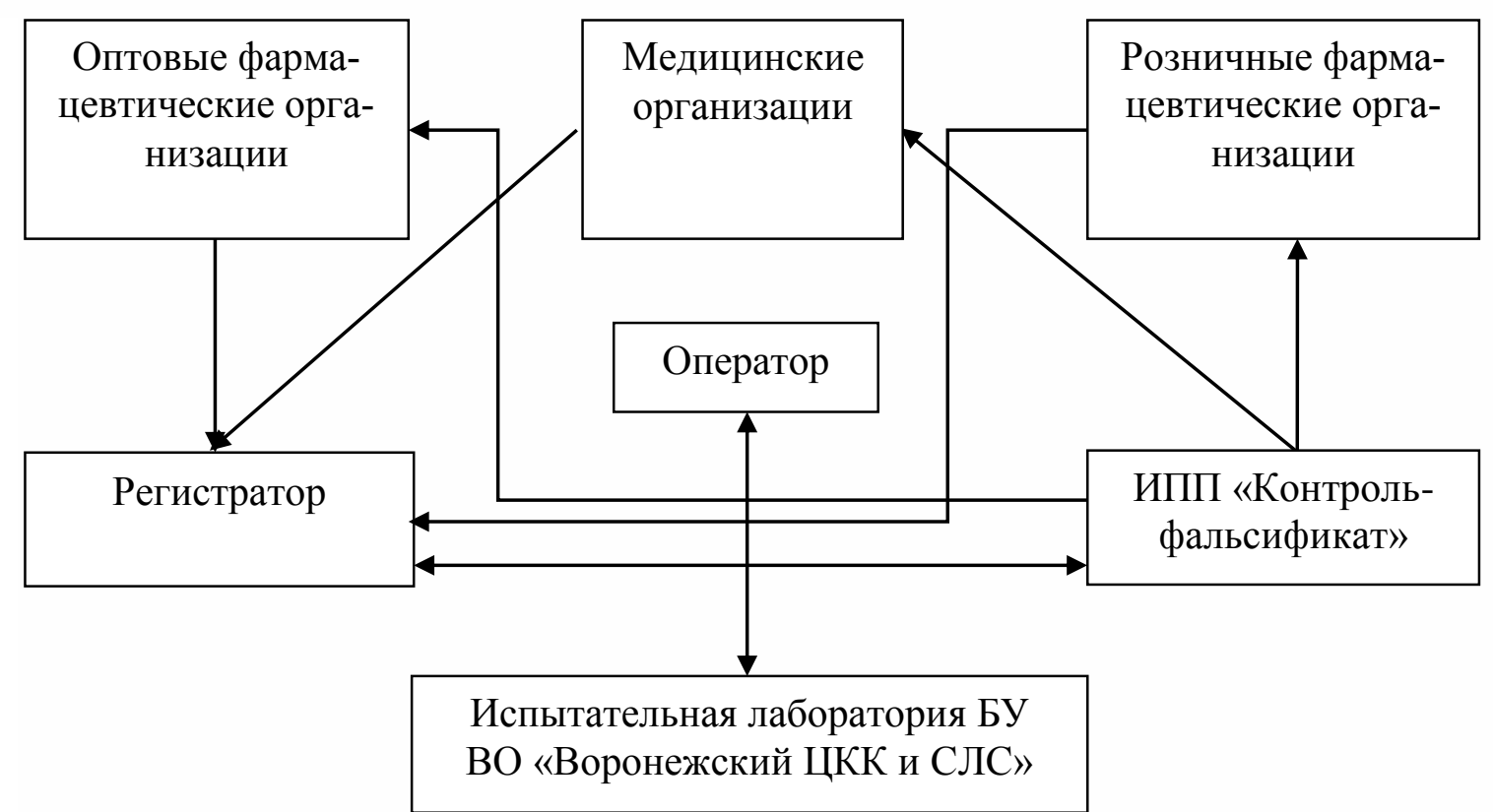

Рис. 4. Схема информационно-аналитического скрининга партий ЛП

Fig. 4. Scheme of informational and analytical screening of medicines

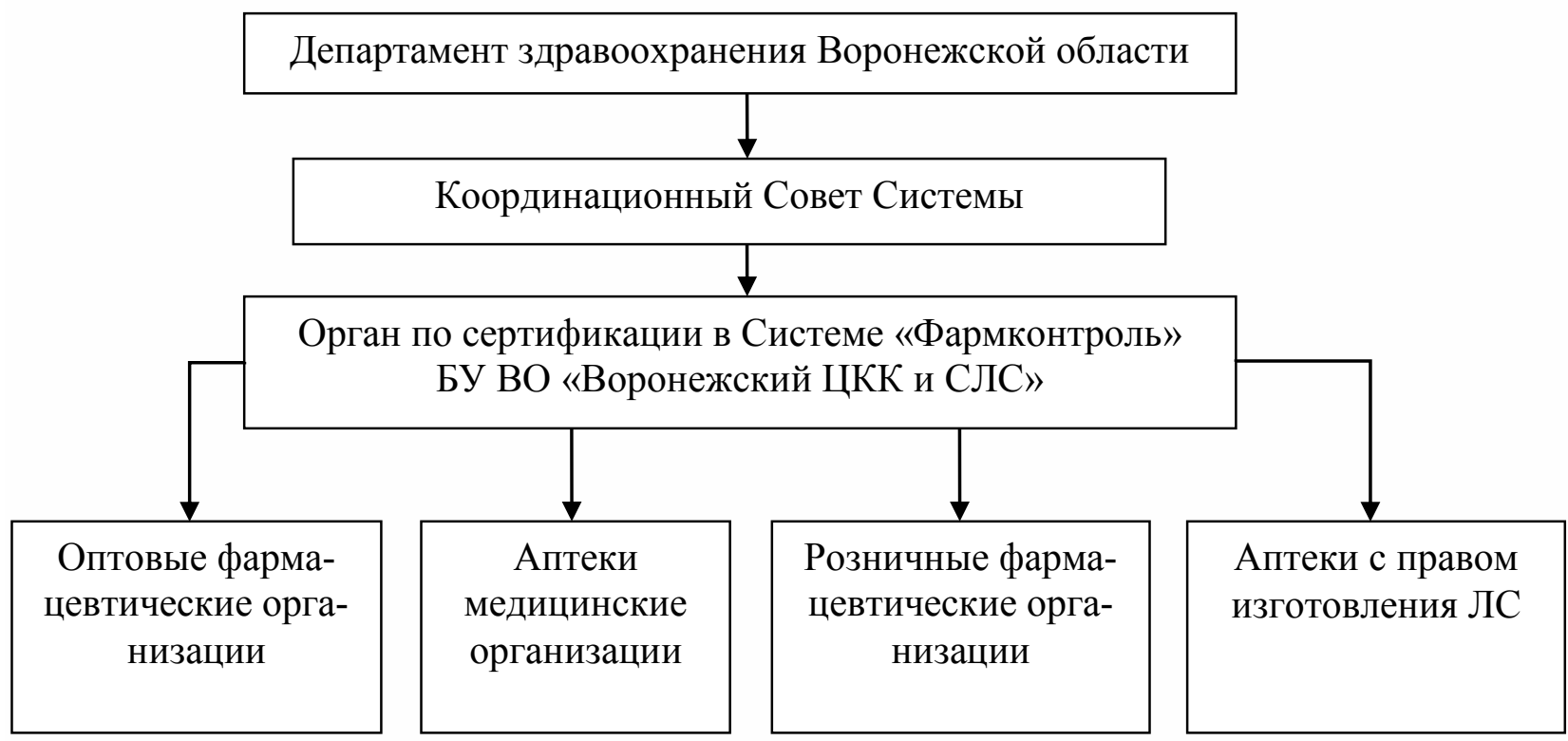

Рис. 5. Схема системы добровольной сертификации «Фармконтроль»

Fig. 5. Scheme of system of voluntary sertification «Pharmcontrol»

Далее рассмотрены результаты многоуровневой системы качества и безопасности лекарств на территории Воронежской обла- сти за период с 2013 года до 2017 года, представленные на рис. 6-8 и в таблице 2. 


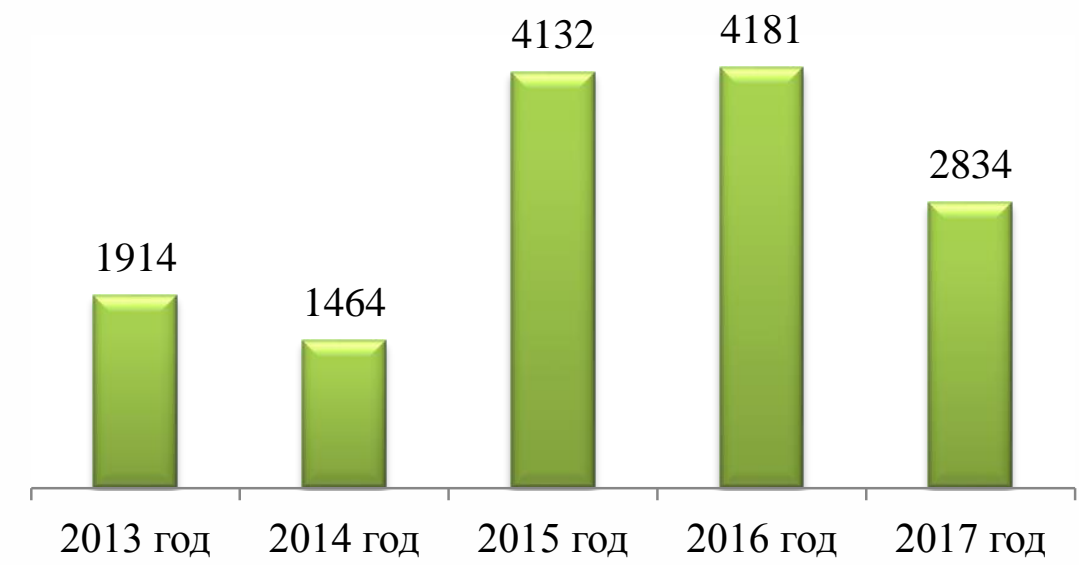

Рис. 6. Результаты лабораторного контроля ввозимых партий ЛП

Fig. 6. Results of laboratory control for imported medicines

839305

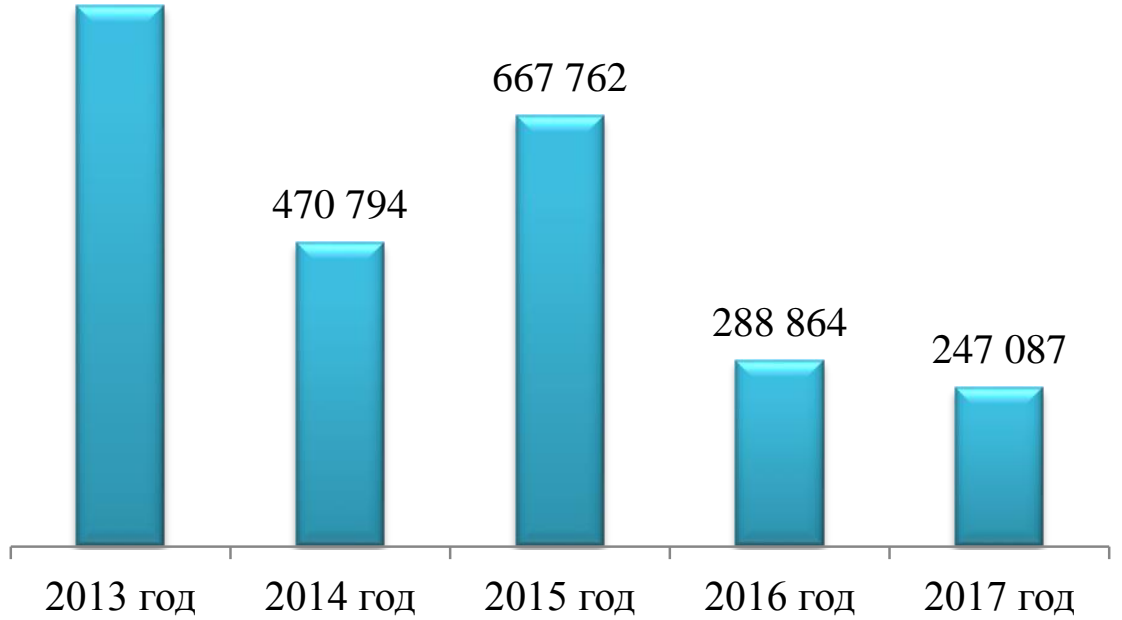

Рис. 7. Информационно-аналитический скрининг партий ЛП

Fig. 7. Informational and analytical screening of medicines

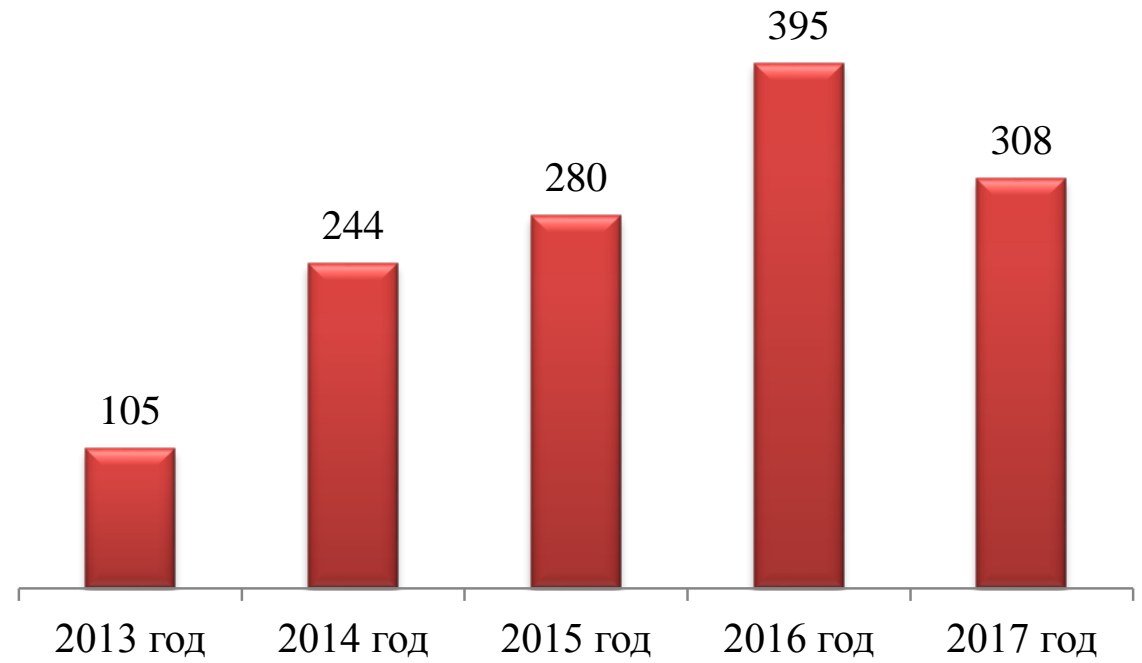

Рис. 8. Результаты целевого мониторинга качества ЛП

Fig. 8. Results of the targeted monitoring for medicines 
Таблища 2

Результаты мониторинга безопасности ЛС на территории Воронежской области

Table 2

Results of safety monitoring for medicines in Voronezh region

\begin{tabular}{|c|c|c|c|}
\hline \multirow{2}{*}{ Год } & \multicolumn{2}{|c|}{ Количество НПР } & \multirow{2}{*}{ Количество ЛП } \\
\cline { 2 - 3 } & Всего & Из них «серьезных» & 52 \\
\hline 2013 & 45 & 24 & 52 \\
\hline 2014 & 45 & 10 & 79 \\
\hline 2015 & 55 & 30 & 143 \\
\hline 2016 & 88 & 30 & 243 \\
\hline 2017 & 185 & 71 & 569 \\
\hline Всего & 418 & 165 & \\
\hline
\end{tabular}

По результатам мониторинга качества ЛС за период с 2013 по 2017 год были выданы сертификаты системы менеджмента качества
«Фармконтроль» в количестве, приведенном на рис. 9.

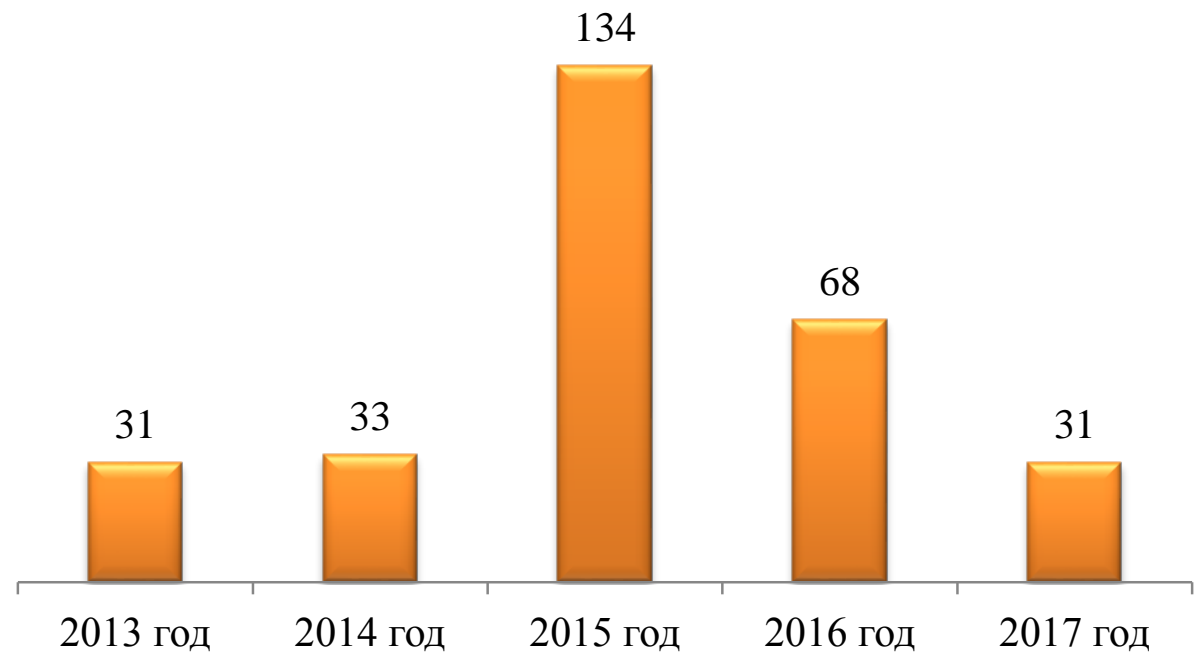

Рис. 9. Количество выданных сертификатов системы менеджмента качества «Фармконтроль»

Fig. 9. Number of given quality management certificates «Pharmcontrol»

\section{Выводы}

Из приведенных в данном обзоре сведений о результатах работы региональной системы мониторинга качества и безопасности лекарственных средств можно сделать вывод, что, не смотря на наблюдаемое снижение количества выявленных фальсифицированных и лекарственных препаратов ненадлежащего качества, необходимость создания комплексной единой системы обеспечения качества лекарственной продукции, как на региональном так и на федеральном уровнях до сих пор остается актуальной.
В отношении данной статьи не было зарегистрировано конфликта интересов.

\section{Список литературы}

1. Концепция развития системы государственного контроля качества, эффективности и безопасности лекарственных средств (система качества фармацевтических продуктов) [Электронный ресурс] // Аптечный бизнес. 2008. URL: http://www.rsn-ing.ru/index.php/reglic/164-20102106-37-09.html (дата обращения: 28.11.2017).

2. Косенко В.В., Беланов К.Ю., Глаголев С.В., Рогов Е.С., Тарасова С.А. Совершенствование системы государственного контроля качества 
лекарственных средств // Вестник Росздравнадзоpa. 2014. 5. C. 48-55.

3. Закон Воронежской области от 30 ноября 2005, №79-О3: “О лекарственном обеспечении населения Воронежской области" (в ред. Закон Воронежской области от 10 июня 2014 г. N 90О3). Собрание законодательства Российской Федерации.

4. Каштанова О.А., Сафиулин Р.С., Я.В. Грибова, Г.И.Хусаинова Информационнокомпьютерные технологии для оптимизации системы контроля качества лекарственных средств в Астраханской области // Вестник Росздравнадзора. 2012. 2. С. 61-64.

5. Морозова Т.Е., Хосева Е.Н. Актуальные вопросы контроля качества, эффективности и безопасности лекарственных средств отечественного производства // Клиническая фармакология и терапия. 2012. 2. С. 54-58.

6. Приказ департамента здравоохранения Воронежской области от 29.09.2010, №1363: «Об утверждении Положения о порядке проведения мероприятий, направленных на предотвращение поступления фальсифицированных и недоброкачественных лекарственных средств на территорию Воронежской области в редакции приказа от 19.10.11г. №1670, для проведения мероприятий, направленных на предотвращение поступления фальсифицированных и недоброкачественных лекарственных средств на территорию Воронежской области и проведение мониторинга качества ЛС», Собрание законодательства Российской Федерации.

7. Приказ департамента здравоохранения Воронежской области от 02.06.2011, №818: «О создании на территории Воронежской области системы добровольной сертификации». Собрание законодательства Российской Федерации.

8. Приказ департамента здравоохранения Воронежской области от 05.08.2015, №1567: «О Региональном центре безопасности лекарственных средств", в редакции приказа от 12.10 .15 г. № 2121». Собрание законодательства Российской Федерации.

9. Приказ Минздравсоцразвития России от 23.08.2010, № 706н: «Об утверждении правил хранения лекарственных средств». Собрание законодательства Российской Федерации.

10. Приказ Министерства здравоохранения РФ от 31.08.2016, №646н: «Об утверждении Правил надлежащей практики хранения и перевозки лекарственных препаратов для медицинского применения». Собрание законодательства Российской Федерации.
11. Приказ Министерства здравоохранения РФ 31.08.2016, №647н: «Об утверждении Правил надлежащей аптечной практики лекарственных препаратов для медицинского применения». Coбрание законодательства Российской Федерации.

12. Федеральный закон Российской Федерации от 12.04.2010, №61-Ф3: «Об обращении лекарственных средств (с изменениями и дополнениями)». Собрание законодательства Российской Федерации, 84 с.

13. Хосева Е.Н., Морозова Т.Е. Организация контроля качества, эффективности и безопасности лекарственных средств на государственном уровне // Качественная клиническая практика. 2013. 2. C. 53-58.

\section{References}

1. Pharmacy business (2008), "Concept of development of the system of state quality control, efficacy and safety of medicines (quality system of pharmaceutical products», available at: http://www.rsn-ing.ru/index.php/reglic/164-20102106-37-09.html, (accessed: 28.11.2017). Russian.

2. Kosenko, V.V., Belanov, K.Y., Glagolev, S.V., Rogov, E.S., Tarasova, S.A. (2014), "Sovershenstvovaniye sistemy gosudarstvennogo kontrolya kachestva lekarstvennykh sredstv", Vestnik Roszdravnadzora, 5, 48-55. Russian.

3. Law of the Voronezh Region of (2005), No. 79-OZ: "On Drug Provision of the Population of the Voronezh Region" (as amended by the Law of the Voronezh Region of June 10, 2014 No. 90-OZ), Legislative Assembly, Voronezh, Russian Federation. Russian.

4. Kashtanova, O.A., Safiulin, R.S., Gribova, Y.V., Khusainova, G. I. (2012), "Information and computer technologies for optimization of the quality control system for medicines in the Astrakhan region", Bulletin of Roszdravnadzor, 2, 61-64. Russian.

5. Morozova, T. E., Khoseva, E. N. (2012), "Actual Issues of Quality Control, Efficiency and Safety of Domestic Medicines", Clinical Pharmacology and Therapy, 2, 54-58. Russian.

6. Order of the Department of Health (2010), No. 1363: "On approval of the Regulation on the procedure for measures aimed at preventing the receipt of falsified and inferior medicines on the territory of the Voronezh Region" in the wording of the order of October 19, №1670, for carrying out activities aimed at preventing the receipt of counterfeit and substandard medicines on the territory of the Voronezh region and conducting quality monitoring of drugs, Meeting of Legislation, Moscow, Russian Federation. Russian. 
7. Order of the Department of Health (2011), No. 818: "On the establishment of a voluntary certification system in the Voronezh Region", Meeting of Legislation, Moscow, Russian Federation. Russian.

8. Order of the Department of Health (2015), No. 1567: "On the Regional Center for the Safety of Medicines", in the wording of the order of 12.10.15. No. 2121, Meeting of Legislation, Moscow, Russian Federation. Russian.

9. Order of the Ministry of Healthcare and Social Development of Russia (2010), No. 706н: "On approval of rules for the storage of medicinal products", Collection of Legislation, Moscow, Russian Federation. Russian.

10. Order of the Ministry of Health of the Russian Federation (2016), No. 646n: "On the Approval of the Rules of Good Practice for the Storage and Transport of Medicinal Products for Medical Use", Collection of Legislation, Moscow, Russian Federation. Russian.

11. Order of the Ministry of Health of the Russian Federation (2016), No. 647n: "On the Approval of the Rules for the Proper Pharmacy Practice of Medicinal Preparations for Medical Use", Meeting of Legislation, Moscow, Russian Federation. Russian.

12. Federal Law of the Russian Federation (2010), No. 61-FZ: "On the circulation of medicines" (with amendments and additions), Legislative Assembly, Moscow, Russian Federation, 84. Russian.

13. Khoseva, E. N., Morozova, T. E. (2013), "Organization of quality control, efficacy and safety of medicines at the state level", Qualitative clinical practice, 2, 53-58. Russian.

Селютин Олег Анатольевич, директор Бюджетного Учреждения Здравоохранения Воронежской Области "Воронежский Центр Контроля Качества и Сертификации Лекарственных Средств"

Selyutin Oleg Anatolyevich, Director of the Budgetary Health Care Institution of the Voronezh Region "Voronezh Center for Quality Control and Drug Certification" 